Apis mellifica (bive bee) on the above bed confined itself to the mignonette. This remark applies to several individuals. Chester, August 17 AlfRed O. WALker

\section{A Meteor}

A BeAUTIFUr meteor was seen from this place on Sunday evening, August 19, at 10.3 precisely. Owing to the brilliancy of the moon, stars of the first magnitude were but faintly seen. I should say the size and brilliancy of the meteor was greatly in excess of the planet Venus at it: best. It was visible as far as I could conjecture about three seconds, and pursued a course of probably 45 or 50 degrees, proceeding from a point a few degrees to the eastward of, and higher than, the north star. It moved almost in a straight line downwards with an inclination to the left. When it had got about half of its whole visible course, it seemed to get blue in colour, and threw off a mass of red sparks, and continued for the rest of the distance, when it appeared to burst, and the disjected fragments were red and visible for a few moments. The colour for the most part was very much like that of Venus, indeed, for the whole of the course, except where it seemed to turn blue.

Lansdowne Road, Wimbledon, S.W., August 2 I

I SAW a very brilliant meteor from the promenade here last night (Sunday, August 19), at ro.3 p.m. It passed along the eastern sky and vanished over the summit of the Little Orme. The meteor was, I think, more brilliant than Venus at her brightest, though the full moon was shining not far off and very few stars were visible. The path was northward, nearly horizontal, inclined a little downwards, about $10^{\circ}$ or $12^{\circ}$ above the horizon, apparently much foreshortened, for the motion was very slow-not faster than that of balls falling from a rocket white light, slightly tinged with blue. The meteor divided, and left one large and I think several smaller portions behind it, all vanishing together. It should have been seen overhead towards the coast of Yorkshire.

Llandudno, August 20

\section{Animal Intelligence}

A CIRCUMSTANCE exceedingly illustrative of the sagacity of the horse was witnessed by myself in the neighbourhood of Nottingham. I had been out for a stroll by way of recreation, returning home across some fields by the Trent side, and when nearly opposite Clifton Grove I stopped a short time to watch a man angling in the river, when suddenly my attention was drawn to a mare with her foal, not many yards distant from where I was standing, open two gates which were vice versa, closing with a strong spring. Her modus operandi was to place her nose in between the two gates and force one gate open with her side, while she had no little difficulty in opening the other for the purpose of getting through. I have learnt that the animal had not been trained to do this, but taught by natural instinct, and so cleverly was it done that man could scarcely have performed the action better. Thinking this instance of sagacity wight be interesting to some of our naturalists, I take the liberty of forwarding same in order that you may insert it in your valuable paper.

9, Charlotte Street, Nottingham

F. WELCH

MR. H. Cecrl's communication respecting the cat and the chicken, at p. 320 of your present volume, reminds me of an instance of the attachment of a cat to its natural prey which is still more remarkable, as there was no "maternal stopy $\eta$ " in question.

Some years ago we had a young emasculated tom cat. When it was nearly full grown we had two young white rabbits brought in which had lost their mother. These were kept in the kitchen, and fed by pouring milk into their mouths with a spoon. They were placed in a basket at night and covered up to protect them from the cat, which was in the habit of catching wild rabbits. One morning the cover was found to have been removed by the cat, which was lying in the basket with the little rabbits. From that time he took charge of them, teaching them to lap milk and watching over them like a mother, even to the extent of driving them home when they grew older and rambled out from the kitchen. The friendship continued till the rabbits grew up, when we lost them by disease.

Chester, August I 7

\section{"Birds and Cholera"}

IN refererence to "H. M. C's." letter in this week's NATURE (p. 366), it is interesting to recall how the traveller Jackson, speaking of the playue that occurred in West Barbary when he was there, says, "The birds of the air fled away from the abodes of men." Thomas Moore, in "Paradise and the Peri," refers to this fact.

E. S. T.

August 18

\section{LIQUID FILMS AND MOLECULAR MAGNITUDES}

SIR WILLIAM THOMSON'S lecture on "The Size of Atoms," which has recently been published in NATURE, will undoubtedly increase the interest felt in measurements which throw any light upon the values of molecular magnitudes.

We have for some time been engaged in investigating the properties of very thin liquid films, and in our last communication to the Royal Society (of which only an abstract has been hitherto published, but which will appear in a forthcoming number of the Philosophical Transactions) we have described two independent methods by which we have obtained concordant measurements of the thickness of soap films in the last stage of tenuity, viz. when exhibiting the black of the first order of Newton's rings.

The paper had not been sent in to the Royal Society at the time when Sir Wm. Thomson's lecture was delivere I, but, on receiving the abstract, he has been good enough to express his approval of our methods and interest in our results, and to raise some questions as to the relation hetween the observations of Newton and ourselves, the further discussion of which he thinks would be interesting to the readers of NATURE.

We propose therefore briefly to discuss the facts which bear upon the points raised by Sir Wm. Thomson, and to describe our methods of experiment so far as may be necessary to make the discussion intelligible.

For thicknesses greater than those which correspond to colours of the first order, the tint displayed affords to a practised eye (when combined with a knowledge of the angle of incidence and refractive index) a very accurate measure of the thickness of a film. In some experiments of our own, in which on more than 500 occasions two independent but simultaneous measures were made of film-thicknesses by means of two beams of light, incident at different angles, we found that the two values obtained agreed to within i per cent. in 52 measures out of every hundred, to within 2 per cent. in 84 , and to within $3 \mathrm{per}$ cent. in 95. All these observations were made in the second and higher orders. The colours of the first order vary from point to point too slowly to enable trustworthy estimates of the thickness to be made, ard when the black of the first order is reached the eye informs us only that the thickness must be less than a certain value, but affords no further indications as to what it really is. The fact that it is extremely small, and the possibility that it may be related to the magnitude of the so-called "radius of molecular attraction," invest the problem of the determination of this thickness with special interest. We have succeeded in solving it by two methods. In each an assumption has to be made for which there is no direct experimental evidence. In each case, however, the assumption is different, and the fact that the mean results obtained by the two methods are in close accord is sufficient to show that, although there is still room for further inquiry, the mean thickness of the black soap films examined was correctly determined to within a fraction of a millionth of a millimetre.

The first method consisted in measuring the electrical resistance of a cylindrical black soap film, and deducing the thickness from Ohm's law, on the assumption that the 